\title{
RESEARCH REGARDING PHYSICAL TESTING IN THE MILITARY PENTATHLON AT THE 50 M RACE WITH OBSTACLES
}

\author{
Ioan Sabin SOPA \\ “Lucian Blaga” University, Sibiu, Romania \\ sopa_sabin@yahoo.com \\ Marcel POMOHACI \\ “Lucian Blaga” University, Sibiu, Romania \\ marcelpomohaci@yahoo.com
}

\begin{abstract}
The research started from the necessity of finding new ways to physical test the military students that are part of the military pentathlon $50 \mathrm{~m}$ race with obstacles team. The research methods used was the experiment method, using two groups: the first group was the control group and the second the experiment group. The experiment consisted in testing the students at: $50 \mathrm{~m}$ speed running, $800 \mathrm{~m}$ resistance running, push-ups, and specific testing like: $50 \mathrm{~m}$ swimming with obstacles, $8 \mathrm{~km}$ run in varied terrain.

The results of our investigation showed that calculation of the statistical significance of the differences between the averages of the two samples showed significant values at $p>0.05, n-1$, at the following parameters: running $800 \mathrm{~m}$ $(t=2.71>2.13-p=0.05)$; push-ups $(t=3.01>2.95-p=0.05)$; freestyle swimming 50m $(t=2.81>2.13-p=0.05)$.
\end{abstract}

KEYWORDS: physical testing, military pentathlon, military sport, $50 \mathrm{~m}$ race with obstacles

\section{Introduction}

The area of the military pentathlon has developed spectacularly from one edition to the next. "Today, more than 30 nations are present in the circuit of international pentathlon competitions. Most of the time the military pentathlon is included in the World Military Games” (Ene, 2003, p. 205).

"Modern pentathlon is a combined athletic game in which final scores represent an aggregate of individual event scores from fencing, swimming, horseback riding, pistol shooting, and running" (Lim, Yoon, Jeong \& Kim, 2018, pp. 62-70). "This game was initiated in ancient Greece with the purpose of testing the general physical strengths of Greek soldiers" (Jeong, 2006).

"The theoretical basis - The results of the scientific researches elaborated in recent years by numerous authors" (Drăgănescu, 2000; Dragnea, 2002; Râşneac, 2004), "broadened the area of representations about the educational potential of physical education in military higher education. The complex psychomotor and personality qualities have a formative role in the educational process of the future component of a military representative team" (Epuran, 2001, pp. 324-336). 
"The development of predictive models of battlefield physical performance can be of significant value to the military by (Williams \& Rayson, 2006) providing advance knowledge to military leaders about the capabilities of their troops, thereby enhancing military decision-making, (Rayson, Holliman \& Belzavin, 2000, pp. 73105) aiding in the selection of personnel for units expected to face demanding physical challenges, (Harman et al., 2008, pp. 36-41) providing a focus for physical training by identifying what physical abilities are essential to battlefield performance, and (Pandorf et al., 2002, 179-189) providing an important tool for the evaluation of military physical training programs".

Knowing the main characteristics of the particularly complex and difficult test, namely $50 \mathrm{~m}$ swimming with obstacles to the military pentathlon, requires its introduction into the curriculum, namely in the new analytical program, which will contribute substantially not only to the achievement of the specific physical training objectives, but especially in the technical and psychomotor training of military students on their future career as an officer. By its specificity, the 50meter-long obstacle swim does not require athlete's only general physical training, but also a very good psychomotor training.

"In military physical activity research papers, scientist analyzed anthropometric parameters and also have been aiming at testing their relationship with physical fitness (Kobermann \& Mayhew, 2012) and monitoring the effectiveness of military physical training programs" (Wen-chyuan Chen et al., 2007, pp. 6-12).

"Determined by these circumstances in the composition of a national military pentathlon representative, we are faced with a multitude of shortcomings in terms of rationalizing as a structure and content of a specific training system” (Ene, 2003, p. 205).

\section{Objectives of the Research}

The objectives of our research were focused on testing physical parameters of military students that participate in the $50 \mathrm{~m}$ swimming pentathlon with obstacles. The research consisted in applying both land physical tests and in water physical test, following the development of motor qualities (speed, strength, coordination and resistance) and also finding new ways of training the military students for the $50 \mathrm{~m}$ swimming pentathlon with obstacles.

\section{Research Sample}

In our research we used two groups, the first group, the experiment group, was formed by 30 military students with age between 18-22 years old components of the pentathlon military team, the second group, the control group, was formed by 30 military students with the same age between 18-22 years old that practice military physical education.

\section{Research Method}

Testing general and specific physical training

Testing the general physical training assessment of the level of physical training, or the expression of the degree of development of each of the motor qualities, is achieved through the tests of the International Physical Fitness Test (F.I.E.P.), known as the "Standard Fitness Test". Considering that there is no specific analytical program in the country at the level of the military physical education with the subsystem for $50 \mathrm{~m}$ obstacles, we considered it necessary to include special physical training samples: speed running on $50 \mathrm{~m}$; running resistance on a distance of $800 \mathrm{~m}$; pushups; swimming $50 \mathrm{~m}$ free.

The test of $50 \mathrm{~m}$ speed running. The test is performed with a standing start with a stopwatch. The result is recorded in seconds and tens of seconds.

The test of resistance running on $800 \mathbf{m}$. The test takes place on flat terrain, 
with a single try. Changing the running in to walking is considered abandon. The result is expressed in minutes and seconds.

The test of pushups. The test is performed from the characteristic position of this exercise. The pace of execution is chosen by the subject. The result is the number of properly executed pushups. The test is not recorded counter-clockwise.

Test of $50 \mathrm{~m}$ free style swimming. The subject is swimming on $50 \mathrm{~m}$ distance with a start at the beep on the block start. The test is performed counter-clockwise, and the performances of the subjects is recorded in seconds and tens of seconds.

\section{Testing specific physical training}

During the testing of the specific physical training, we applied a series of tests characteristic to the military pentathlon evidence:

- swimming with obstacles (50 m);

- running in varied terrain (8 km).

\section{Obstacle swimming}

This test was carried out in specific conditions to swimming over a distance of $50 \mathrm{~m}$. The specific obstacles were:

- The first obstacle - the gate;

- The second obstacle - the raft;

- The third obstacle - table (fixed platform);

- The forth obstacle - mobile (transverse) beam.

The achieved performances were recorded in seconds and tenths of a second. Penalties for this test were applied in accordance with the International Assessment System as follows:

- two wrong starts (default yellow card), a penalty of 2 seconds of the performed performance;

- the wrong start after yellow (default red) is a disqualification.

\section{Running in a varied terrain}

The test is the last specific test of the military pentathlon. Depending on the results obtained in the previous specific test to the military pentathlon, each subject has obtained the starting order number as follows: the competitor who has accumulated the maximum score after the first four tests starts at runtime 0 (first). The other competitors, based on the difference in accumulated points, will take the handicap start (the difference in points is the start difference in seconds).

\section{Results}

Analyzing and interpreting data in general physical training tests (experimental stages 1 and 2)

The process of choosing the general physical training tests was motivated by the fact that through them an objective assessment of the level and pace of evolution of the general motor skills can be made. As an expression of the degree of development of each motor skill, in this study, we applied for the objective assessment of general physical training, the following tests: $50 \mathrm{~m}$ speed run, $800 \mathrm{~m}$ resistance running, pushups, 50 freestyle swimming.

The tests were applied in the experimental stage 1 twice, and the results obtained by the subjects of the two groups were statistically processed. From the analysis of the data recorded in the initial testing (Table no. 1), it is observed that the performance averages obtained by the subjects of the two samples are equally or approximately equal. Also in this test, the calculation of the difference between the averages of the obtained results shows insignificant values at the degree $\mathrm{n}-1$ and the statistical significance stage of 0.05 . 
Table no. 1

Comparative analysis of group average that characterizes the general physical training of military students initially tested in experimental stage 1

\begin{tabular}{|c|c|c|c|c|c|}
\hline \multirow{2}{*}{$\begin{array}{l}\text { No. } \\
\text { Cha. }\end{array}$} & \multirow{2}{*}{ Compared parameters } & \multicolumn{2}{|c|}{$\bar{X} \pm m$} & \multicolumn{2}{|c|}{ Criteria } \\
\hline & & The control group & The experiment group & "t" & “p” \\
\hline 1 & Speed running $50 \mathrm{~m} \mathrm{(s)}$ & $7.50 \pm 0,04$ & $7.40 \pm 0,08$ & 2.00 & $>0.05$ \\
\hline 2 & $\begin{array}{l}\text { Resistance running } \\
800 \mathrm{~m}(\mathrm{~s})\end{array}$ & $157.00 \pm 0,69$ & $156.00 \pm 0,01$ & 0.69 & $>0.05$ \\
\hline 3 & Pushups (no) & $24.00 \pm 0,53$ & $25.00 \pm 0,61$ & 1.56 & $>0.05$ \\
\hline 4 & $\begin{array}{l}\text { Free style swimming } \\
\text { on } 50 \mathrm{~m}(\mathrm{~s})\end{array}$ & $40.00 \pm 0,03$ & $39.20 \pm 0,07$ & 0.83 & $>0.05$ \\
\hline
\end{tabular}

Table no. 2

Comparative analysis of group average that characterizes general physical training of military students finally tested in experimental stage 1

\begin{tabular}{|c|c|c|c|c|c|}
\hline \multirow{2}{*}{$\begin{array}{l}\text { No. } \\
\text { Cha. }\end{array}$} & \multirow{2}{*}{ Compared parameters } & \multicolumn{2}{|c|}{$\bar{X} \pm m$} & \multicolumn{2}{|c|}{ Criteria } \\
\hline & & The control group & The experiment group & “t” & “p” \\
\hline 1 & Speed running $50 \mathrm{~m}$ (s) & $7.20 \pm 0.04$ & $7.10 \pm 0.08$ & 2.00 & $>0.05$ \\
\hline 2 & $\begin{array}{l}\text { Resistance running } \\
800 \mathrm{~m}(\mathrm{~s})\end{array}$ & $148.00 \pm 0.69$ & $145.00 \pm 0.01$ & 0.69 & $>0.05$ \\
\hline 3 & Pushups (no) & $27.80 \pm 0.53$ & $29.00 \pm 0.61$ & 1.56 & $>0.05$ \\
\hline 4 & $\begin{array}{l}\text { Free style swimming } \\
\text { on } 50 \mathrm{~m}(\mathrm{~s})\end{array}$ & $39.20 \pm 0.03$ & $38.40 \pm 0.07$ & 0.83 & $>0.05$ \\
\hline
\end{tabular}

At the end of the experimental phase, the application of the tests generated changes in the performance averages obtained in most parameters (Table no. 1). From the analysis of the dynamics of the obtained results described graphically (Figure no. 1), the performances averages obtained from the final test are representative for $50 \mathrm{~m}$ freestyle swimming test. The significance of the mean differences in the final test between the two samples is represented by significant values at $p=0.01$ degree of $n-1$, in favor of the experimental group (for the sample above $t$ is $2.22>2.13$ at $n-1)$.

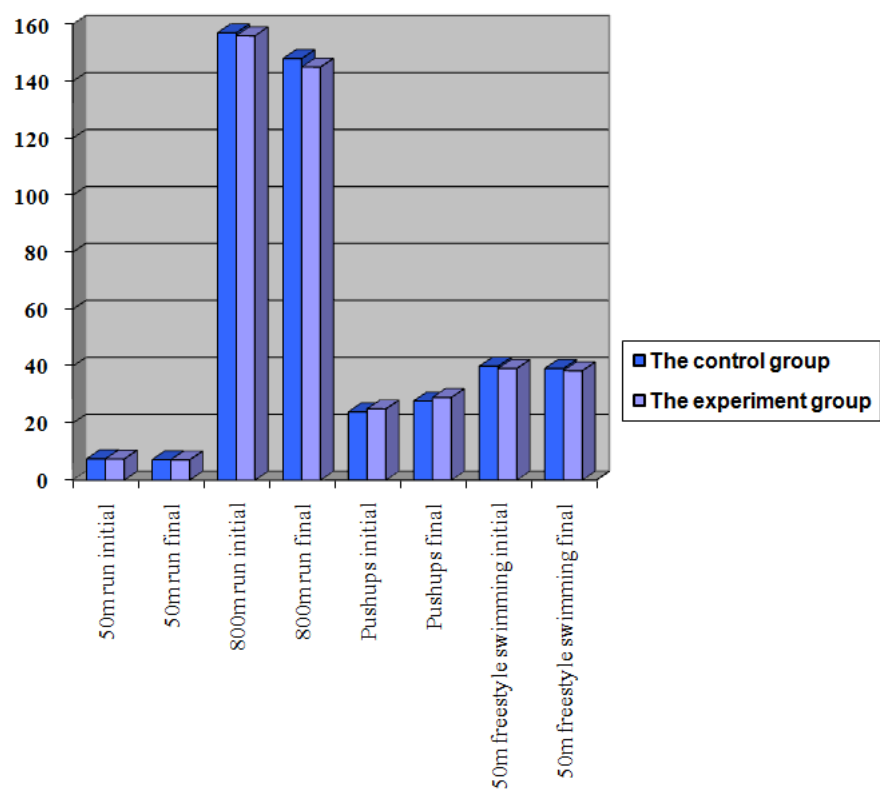

Figure no. 1: Dynamics of general physical training test results in the experimental stage 1 
The level of development of general physical training has seen an important improvement at the end of the research, as demonstrated by the results of the experimental group subjects (Table no. 3).

Table no. 3

Comparative analysis of group average that characterizes the general physical training of military students final tested in the experimental stage 2

\begin{tabular}{cccccc}
\hline \multirow{2}{*}{$\begin{array}{c}\text { No. } \\
\text { Cha }\end{array}$} & \multirow{2}{*}{ Compared parameters } & The control group & The experiment group & “t” & "p" \\
\cline { 2 - 6 } & & $7.20 \pm 0.04$ & $7.10 \pm 0.08$ & 2.00 & $>0.05$ \\
2 & Speed running $50 \mathrm{~m}(\mathrm{~s})$ & $148.00 \pm 0.69$ & $145.00 \pm 0.01$ & 0.69 & $>0.05$ \\
3 & Resistance running 800 m(s) & $27.80 \pm 0.53$ & $29.00 \pm 0.61$ & 1.56 & $>0.05$ \\
4 & Fushups (no) & $39.20 \pm 0.03$ & $38.40 \pm 0.07$ & 0.83 & $>0.05$ \\
\hline
\end{tabular}

Table no. 4

Final test

\begin{tabular}{cccccc}
\hline \multirow{2}{*}{$\begin{array}{c}\text { No. } \\
\text { Cha }\end{array}$} & \multirow{2}{*}{ Compared parameters } & \multicolumn{2}{c}{$\bar{X}$ Criteria } \\
\cline { 2 - 6 } & & The control group & The experiment group & "t” & "p" \\
\hline 1 & Speed running 50 m (s) & $7.10 \pm 0.04$ & $6.98 \pm 0,04$ & 1,60 & $>0.05$ \\
2 & Resistance running 800 m (s) & $141.50 \pm 0,77$ & $136.20 \pm 0,69$ & 2,71 & $<0.05$ \\
3 & Pushups (no) & $29.20 \pm 1,00$ & $34.10 \pm 0,77$ & 3,01 & $<0.01$ \\
4 & Free style swimming on 50 m (s) & $36.70 \pm 0,77$ & $33.80 \pm 0,69$ & 2,81 & $<0.05$ \\
\hline
\end{tabular}

Compared to the performance averages obtained in the initial testing, where we found statistical differences at $\mathrm{p}=0.05, \mathrm{n}-1$, in favor of the experimental group, only at the $50 \mathrm{~m}$ freestyle swimming parameter the, in the final test, we notice significant differences in most parameters. On the comparative analysis basis of the group average characterizing the general physical training, we formed the dynamics of the results obtained in the tests proposed and carried out at this experimental stage.
In Figure no. 4 it can be seen that the mean values increase in final testing for both control group subjects and experimental subjects. The calculation of the statistical significance of the differences between the averages of the two samples shows significant values at $\mathrm{p}=0.05, \mathrm{n}-1$, at the following parameters: running $800 \mathrm{~m}$ $(\mathrm{t}=2.71>2.13-\mathrm{p}=0.05)$; push-ups $(\mathrm{t}=3.01>2.95-\mathrm{p}=0.05)$; freestyle swimming $50 \mathrm{~m}(\mathrm{t}=2.81>2.13-\mathrm{p}=0.05)$.



Figure no. 2: Dynamics of general physical training test results in the experimental phase 2 
As we follow the statistical processing of the performances obtained by the subjects of the experimental study, we notice that the performance environments have progressively increased from one test to the other. If these samples are minimal for the control group subjects, they fall into a normal progression due to the application of the traditional analytical program for the experimental group, the statistically significant performances demonstrate the veracity of the research and the viability of the algorithmic system in the experimental analytical program.

Analyzing and interpreting data in specific physical training tests (experimental stages 1 and 2).

Testing of specific physical training was carried out in the experimental stage 1 by means of the tests of the military pentathlon, tests that were applied concurrently to the control and experimental subjects both at the initial stage of the experimental stage 1 and at the end of it. In accordance with the a priori developed research curriculum, it was considered that the military pentathlonspecific tests are the most appropriate tests with practical applicability for the objective establishment of the specific physical training level of military students. The data obtained in the experimental stage 1 were statistically processed (graph 5). After the application of the proposed statistical indicators and the statistical and mathematical methods, the obtained results allowed the comparative analysis of the group media characterizing the specific physical training of the military students both during the initial testing (Table no. 5) and the final testing (Table no. 6).

Table no. 5

Comparative analysis of group average that characterizes the specific physical training of military students initially tested in experimental stage 1

\begin{tabular}{|c|c|c|c|c|c|}
\hline \multirow{2}{*}{$\begin{array}{l}\text { No. } \\
\text { Cha. }\end{array}$} & \multirow{2}{*}{ Compared parameters } & \multicolumn{2}{|c|}{$\bar{X} \pm m$} & \multicolumn{2}{|c|}{ Criteria } \\
\hline & & The control group & The experiment group & "t" & "p" \\
\hline 1 & $\begin{array}{l}\text { Swimming with } \\
\text { obstacles } 50 \mathrm{~m} \text { (s) }\end{array}$ & $44.00 \pm 0.23$ & $43.30 \pm 0.23$ & 1.30 & $>0.05$ \\
\hline 2 & Running 8 km (s) & $1984.00 \pm 2.31$ & $1979.0 \pm 1.54$ & 1.80 & $>0.05$ \\
\hline
\end{tabular}

Table no. 6

Comparative analysis of group average that characterizes the specific physical training of the military students finally tested in the experimental stage 1

\begin{tabular}{cccccc}
\hline \multirow{2}{*}{$\begin{array}{c}\text { No. } \\
\text { Cha. }\end{array}$} & Compared parameters & \multicolumn{2}{c}{$\bar{X} \pm m$} & \multicolumn{2}{c}{ Criteria } \\
\cline { 3 - 6 } & & The control group & The experiment group & "t" & "p" \\
\hline 1 & $\begin{array}{c}\text { Swimming with } \\
\text { obstacles 50 m (s) }\end{array}$ & $43.60 \pm 0.23$ & $41.80 \pm 0.23$ & 2.42 & $<0,05$ \\
2 & Running 8 km (s) & $1972.00 \pm 2.31$ & $1964.0 \pm 1.54$ & 2.08 & $>0.05$ \\
\hline
\end{tabular}

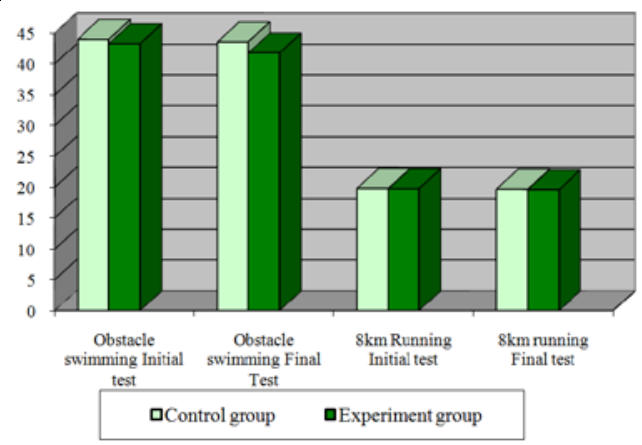

Figure no. 3: Dynamics of the specific physical training test results in experimental stage I 


\section{$50 \mathrm{~m}$ swimming with obstacles}

The test was conducted in swimming conditions over a distance of $50 \mathrm{~m}$, with 4 specific obstacles (gate, raft, table, movable beam). From the comparative analysis of the group media recorded in the initial testing (Table no. 5), we can see that the average performances obtained were approximate in value (44.00 sec for the control group and $43.30 \mathrm{sec}$ for the experiment group). From the graphical representation (Figure no. 4) it was found that in the final testing there was a significant difference between the averages ( $\mathrm{t}$ with the value of $2.42 \times 2.13$ at $\mathrm{n}-1$, $p=0.05$ ), the difference being significant in favor of the experimental group. According to the research plan, the application of the specific physical training tests continued in the experimental stage 2 . The performances recorded by the subjects at all the specific pentathlon tests were statistically processed at the end of the research (Table no. 6). We found that there were statistically significant differences in experimental stage 1 from the comparative study of group average in favor of the experimental group in the obstacle swimming test at n-1, $\mathrm{p}=0.05$, where $\mathrm{t}$ is expressed by $2.42>2.13$, in the second experimental stage, performance averages increased significantly. The swimming test with specific obstacles on the distance of $50 \mathrm{~m}$ has presented for the group's subjects the final test with good performances.

Table no. 7

Comparative analysis of group average that characterizes the specific physical training of the military students initially - finally tested in the experimental stage 2

\begin{tabular}{cccccc}
\hline \multirow{2}{*}{$\begin{array}{c}\text { No. } \\
\text { Cha. }\end{array}$} & \multirow{2}{*}{$\begin{array}{c}\text { Compared } \\
\text { parameters }\end{array}$} & The control group & The experiment group & “t” & "p" \\
\cline { 3 - 6 } 1 & $\begin{array}{c}\text { Swimming with } \\
\text { obstacles 50 m (s) }\end{array}$ & $43.60 \pm 0.23$ & $41.80 \pm 0.23$ & 2.42 & $<0,05$ \\
2 & Running 8 km (s) & $1972.00 \pm 2.31$ & $1964.0 \pm 1.54$ & 2.08 & $>0.05$ \\
\hline
\end{tabular}

Table no. 8 Final test

\begin{tabular}{|c|c|c|c|c|c|}
\hline \multirow{2}{*}{$\begin{array}{l}\text { No. } \\
\text { Cha. }\end{array}$} & \multirow{2}{*}{$\begin{array}{l}\text { Compared } \\
\text { parameters }\end{array}$} & \multicolumn{2}{|c|}{$\bar{X} \pm m$} & \multicolumn{2}{|c|}{ Criteria } \\
\hline & & The control group & The experiment group & “t” & “p” \\
\hline 1 & $\begin{array}{c}\text { Swimming with } \\
\text { obstacles } 50 \mathrm{~m} \text { (s) }\end{array}$ & $40.10 \pm 0,77$ & $37.20 \pm 0,69$ & 3,10 & $<0,01$ \\
\hline 2 & Running 8 km (s) & $1938.00 \pm 3,39$ & $1921.00 \pm 2,77$ & 3,66 & $<0,01$ \\
\hline
\end{tabular}

The experimental group results $37.20 \mathrm{~s}$, is superior to the one recorded by the control group - $40.10 \mathrm{~s}$, with $2.90 \mathrm{~s}$. From the calculation of the statistical significance (Table no. 8), it is observed that the difference between the samples is significant, where $\mathrm{t}$ is 3.10 at $\mathrm{n}-1, \mathrm{p}=0.01$. In the last test of the military pentathlon, running on a varied terrain of $8 \mathrm{~km}$, the subjects of the control group performed an average of $1938.00 \mathrm{~s}$, and the experimental group subjects 1921.00 s. The statistical calculation of the difference between the averages demonstrates the existence of the significant difference between the two samples, which is expressed by $3.66>2.95$ at $\mathrm{p}=0.01, \mathrm{n}-1$. 




Figure no. 4: Dynamics of the specific physical training test results in the experimental phase 2

The comparative study of group averages that characterizes the specific physical training of the military students tested at different stages of our experiment demonstrates that the performance of the subjects of the experimental group has improved statistically significantly, which expresses the veracity of the research.

The results obtained, processed and statistically interpreted in the specific physical training test, allow us to conclude that the structure and content of the analytical program introduced in the educational plan of the experimental group corresponded to the objectives of physical education and military sport.

\section{Discussions}

Through the final testing of the general physical training, it was found that most of the studied parameters have a statistical significance (in 3 of the 4 parameters tested). Significant differences were found with a value of $t=2.71$ at the $800 \mathrm{~m}$ resistance running and $\mathrm{t}=3.01$ pushups, in favor of the experiment group, which demonstrates the value of the research. The implementation of the instructive analytical program with specific themes from the $50 \mathrm{~m}$ obstacle swimming test, respectively the implementation of the movement technologies expressed in the algorithmic models specific to the technical learning of obstacles in the specific pentathlon swimming, determined the achievement of the superior results by the experimental group subjects. Parameters that were researched, specific physical training characteristics, show statistically significant differences in the degree of range $n-1$ and significance stage of $p=0.05$ $(\mathrm{t}=3.10$ for obstacle swimming and $\mathrm{t}=3.66$ for $8 \mathrm{~km}$ running in varied terrain) in favor of the experimental group. The results of the statistical calculation demonstrate the value of the implementation of the specific technical and psychomotor training algorithms in the $50 \mathrm{~m}$ obstacle swimming test. Other scientific research (Ene-Voiculescu \& EneVoiculescu, 2016) found significant results from analyzing the difference between two samples at the $50 \mathrm{~m}$ obstacle swimming (37.50 s for the witness group and $37.20 \mathrm{~s}$ for the experiment group and a $t$ with the value $2.53>2.13$ to $n-1, p=0.05$ ). 


\section{Conclusions}

By implementing a new methodological line of learningconsolidating-improving the technique of obstacles in the physical education and sports lessons, the results were statistically significant at the next level of the parameters: the self-control capacity and coordination in conditions of swimming in the pool, also in conditions of a specific obstacle. The final results confirm the validity of the intervention in the analytical program of the specific technical and psychomotor training approach in the $50 \mathrm{~m}$ obstacle swimming test.

\section{REFERENCES}

Dragnea, A. (2002). Teoria Educaţiei Fizice şi a Sportului. Bucureşti: FEST, 177-186.

Drăgănescu, E. (2000). Optimizarea conţinutului educaţiei fizice privind pregătirea profesional-aplicativă a studenţilor de la universităţile de medicină în baza intensificării procesului de studii. Teză de doctorat, Chişinău, 157-165.

Ene, V. (2003). Orientări moderne în antrenamentul sportiv din pentatlonul militar, Constanţa: Editura Academiei Navale "Mircea cel Bătrân", 205.

Ene-Voiculescu, V., \& Ene-Voiculescu, C. (2016). Operative systems specify to the training in military pentathlon. The 23rd International Conference Knowledge-Based Organization, Vol. XXII, No. 1, Sibiu, România: “Nicolae Bălcescu” Land Forces Academy Publishing House.

Epuran, M. (2001). Psihologia sportului de performanţă. Bucureşti: FEST, 324-336.

Harman, E. A. et al. (2008). Prediction of simulated battlefield physical performance from field-expedient tests. U.S. National Library of Military Medicine, Vol. 173, 36-41.

Jeong, C. S. (2006). Characteristics of performance-related physical fitness and physique in elite modern pentathlon players. Seoul: Korea National University.

Kobermann, A. M., \& Mayhew, J. (2012). Relationship of body mass to army physical fitness test performance in College ROTC cadets. 25th Annual Student Research Conference. Kirksville: Truman State University.

Lim, C. H., Yoon, J. R., Jeong, C. S., \& Kim, Y. S. (2018). An analysis of performance determinants of modern pentathlon athletes in laser-run, a newly-combined event in modern pentathlon. Exercise Science, Vol. 27, No. 1, 62-70.

Pandorf, C. E. et al. (2002). Correlates of load carriage and obstacle course performance among women. U.S. National Library of Military Medicine, Work; Vol. 18, 179-189.

Rayson, M., Holliman, D., \& Belyavin, A. (2000). Development of physical selection procedures for the British Army Phase 2: relationship between physical performance tests and criterion tasks. U.S. National Library of Military Medicine, Ergonomics, Vol. 43, 73-105, DOI:10.1080/001401300184675

Râşneac, B. V. (2004). Utilizarea tehnicii de calcul în evaluarea performanţelor sportive. Braşov: Editura Transilvania, 34-51.

Wen-Chyuan Chen, K. et al. (2007). A study of basic military training on the physical fitness and physical self-concept for cadets. Journal of Physical Education \& Recreation, Vol. 13(2), 6-12.

Williams, A. G., \& Rayson, M. P. (2006). Can simple anthropometric and physical performance tests track training-induced changes in load-carriage ability?. U.S. National Library of Military Medicine, Vol. 171, 742-8. 